\title{
TaMCA4, a Novel Wheat Metacaspase Gene Functions in Programmed Cell Death Induced by the Fungal Pathogen Puccinia striiformis f. sp. tritici
}

\author{
Xiaodong Wang, ${ }^{1}$ Xiaojie Wang, ${ }^{1}$ Hao Feng, ${ }^{1}$ Chunlei Tang, ${ }^{2}$ Pengfei Bai, ${ }^{1}$ Guorong Wei, ${ }^{1}$ Lili Huang, \\ and Zhensheng Kang ${ }^{1}$ \\ ${ }^{1}$ State Key Laboratory of Crop Stress Biology for Arid Areas and College of Plant Protection, Northwest A\&F University, \\ Yangling, Shaanxi 712100, P. R. China; ${ }^{2}$ College of Life Science, Northwest A\&F University, Yangling, Shaanxi, 712100 , \\ P. R. China
}

Submitted 5 November 2011. Accepted 27 January 2012.

\begin{abstract}
Programmed cell death (PCD) is a physiological process to remove redundant or harmful cells, for the development of multicellular organisms, or for restricting the spread of pathogens (hypersensitive response). Metacaspases are cysteine-dependent proteases which play an essential role in PCD. Triticum aestivum metacaspase $4(\mathrm{TaMCA4})$ is a type II metacaspase gene cloned from 'Suwon11' wheat, with typical structural features such as peptidase C14 caspase domain and a long linker sequence between the two subunits. Transient expression of TaMCA4 in tobacco leaves failed to induce PCD directly but enhanced cell death triggered by a mouse Bax gene or a candidate effector gene from Puccinia striiformis f. sp. tritici. Enhancement of PCD was also observed in wheat leaves co-bombarded with TaMCA4. When challenged with the avirulent race of $P$. striiformis f. sp. tritici, the expression level of TaMCA4 in wheat leaves was sharply upregulated, whereas the transcript level was not significantly induced by the virulent race. Moreover, knocking down TaMCA4 expression by virus-induced gene silencing enhanced the susceptibility of Suwon11 to the avirulent race of $P$. striiformis $f$. sp. tritici and reduced the necrotic area at infection sites.
\end{abstract}

Programmed cell death (PCD) is a regulated physiological process of cell death to remove unwanted and damaged cells (Coll et al. 2011; Das et al. 2010). In animals, the most typical form of PCD has been named apoptosis and is defined by a distinct set of morphological and biochemical features, such as cell shrinkage, membrane blebbing, nuclear condensation, and DNA fragmentation (Geske and Gerschenson 2001). During apoptosis, caspases, the principal proteases that are activated and cleave a variety of proteins, ultimately lead to cell death and disintegration (Kitanaka and Kuchino 1999; Kroemer and Martin 2005).

To date, although no functional homologues of animal caspases have been identified in plants, a family of cysteinedependent proteases named metacaspases was found in plants, fungi, and protozoans (Carmona-Gutierrez et al. 2010; Enoksson and Salvesen 2010). Metacaspases, with other cell death proteases, such as vacuolar processing enzyme (VPE) and subtilisin-

Corresponding author: Z. Kang, E-mail: kangzs@nwsuaf.edu.cn

* The $\boldsymbol{e}$-Xtra logo stands for "electronic extra" and indicates that two supplementary tables and one supplementary figure are published online. like serine proteases, share a very complex regulation system due to their mutual substrates and related signal pathways (Woltering 2004). During the last 10 years, both of the structural and functional features of this gene family have been studied in different species. One of the yeast metacaspase genes, $Y C A 1$, was reported to mediate PCD upon peroxide treatment, supporting a role of metacaspase in apoptosis (Madeo et al. 2002). In Botrytis cinerea-infected tomato leaves, the expression level of a metacaspase gene, LeMCA1, was upregulated (Hoeberichts et al. 2003).

In Arabidopsis, there are several metacaspases reported to be involved in plant resistance to pathogen. For instance, a series of Arabidopsis MCA knockout mutants showed significant alterations in sensitivity to the necrotrophic fungus Botrytis spp. (Van Baarlen et al. 2007). Two metacaspases, AtMCl and AtMC2, antagonistically control PCD; thus, AtMC1 is shown to be a positive regulator of cell death and requires conserved caspase-like catalytic residues for its function, whereas AtMC2 negatively regulates cell death (Coll et al. 2010). Another detailed study shows that AtMC4 is a positive mediator of cell death induced by both biotic and abiotic stresses (Watanabe and Lam 2011a).

Metacaspases are divided into two types (type I and type II) according to the structural feature of the linker between the P20-like and P10-like domains; thus, type II metacaspases have a much longer linker between the two subunits (Rahman 2010). There is no evidence of different action modes between these two types (e.g., some metacaspases show autoprocessing whereas others cleavage specific substrates) (Tsiatsiani et al. 2011). The specific roles of different types of metacaspases in plant resistance to a pathogen are largely unknown and debatable. One study shows that two type I Arabidopsis metacaspases (AtMC1 and AtMC3) are upregulated in plants challenged by various bacterial pathogens and none of the type II metacaspases shows any induction (He et al. 2008), whereas another study concludes that all the three type I metacaspases and two type II metacaspases (AtMC5 and AtMC8) are activated upon infection by various bacterial pathogens (Watanabe and Lam 2005). Although different members of metacaspases in Arabidopsis were intensively characterized during the last decade, few investigations of the exact functions of metacaspase genes in wheat or other monocots have been reported.

Stripe rust, caused by Puccinia striiformis f. sp. tritici, is one of the most destructive fungal diseases of wheat worldwide (Chen et al. 2002). Application of wheat stripe rust-resis- 
tant cultivars is considered to be the most effective disease control measure. Over 30 stripe rust resistance genes have been identified in wheat. Recognition of avirulence $(A V R)$ gene products from the pathogen by corresponding resistance
$(R)$ genes in the plant is believed to trigger a hypersensitive response (HR). HR has long been considered to be a rapid PCD, which sacrifices plant cells surrounding the infection site to limit pathogen growth (Katagiri and Tsuda 2010).

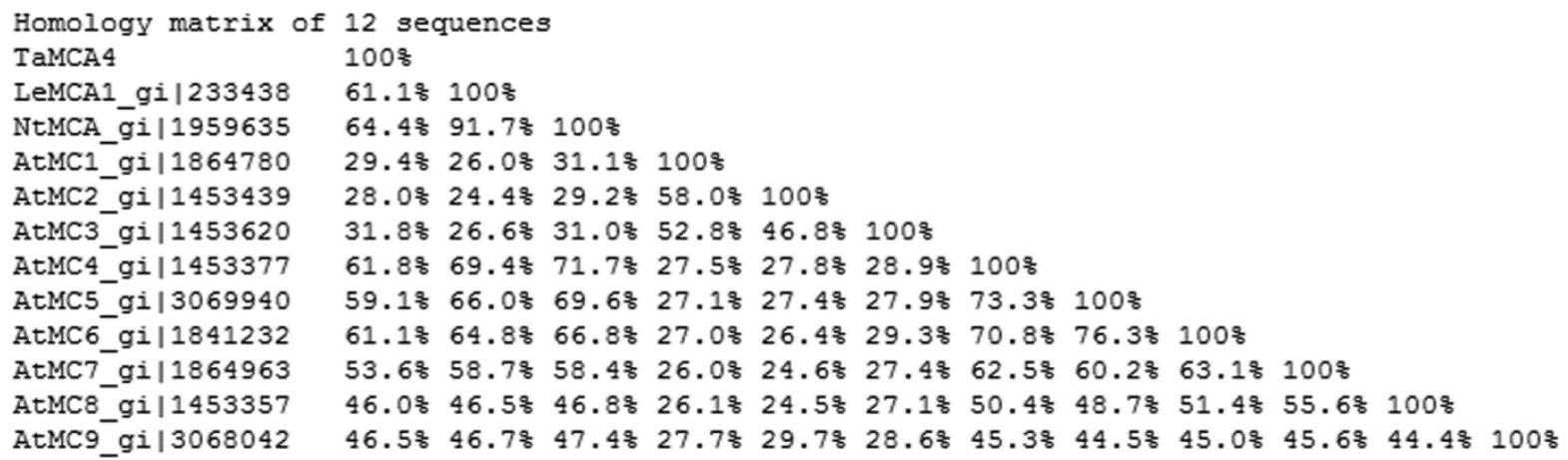

Fig. 1. Homology matrix of Triticum aestivum metacaspase 4 (TaMCA4) and other metacaspase proteins. Calculated using DNAMAN version 6 software. Sequences used in this comparison are from Triticum aestivum (Ta), Nicotiana tabacum (Nt), Lycopersicon esculentum (Le), and Arabidopsis thaliana (At).
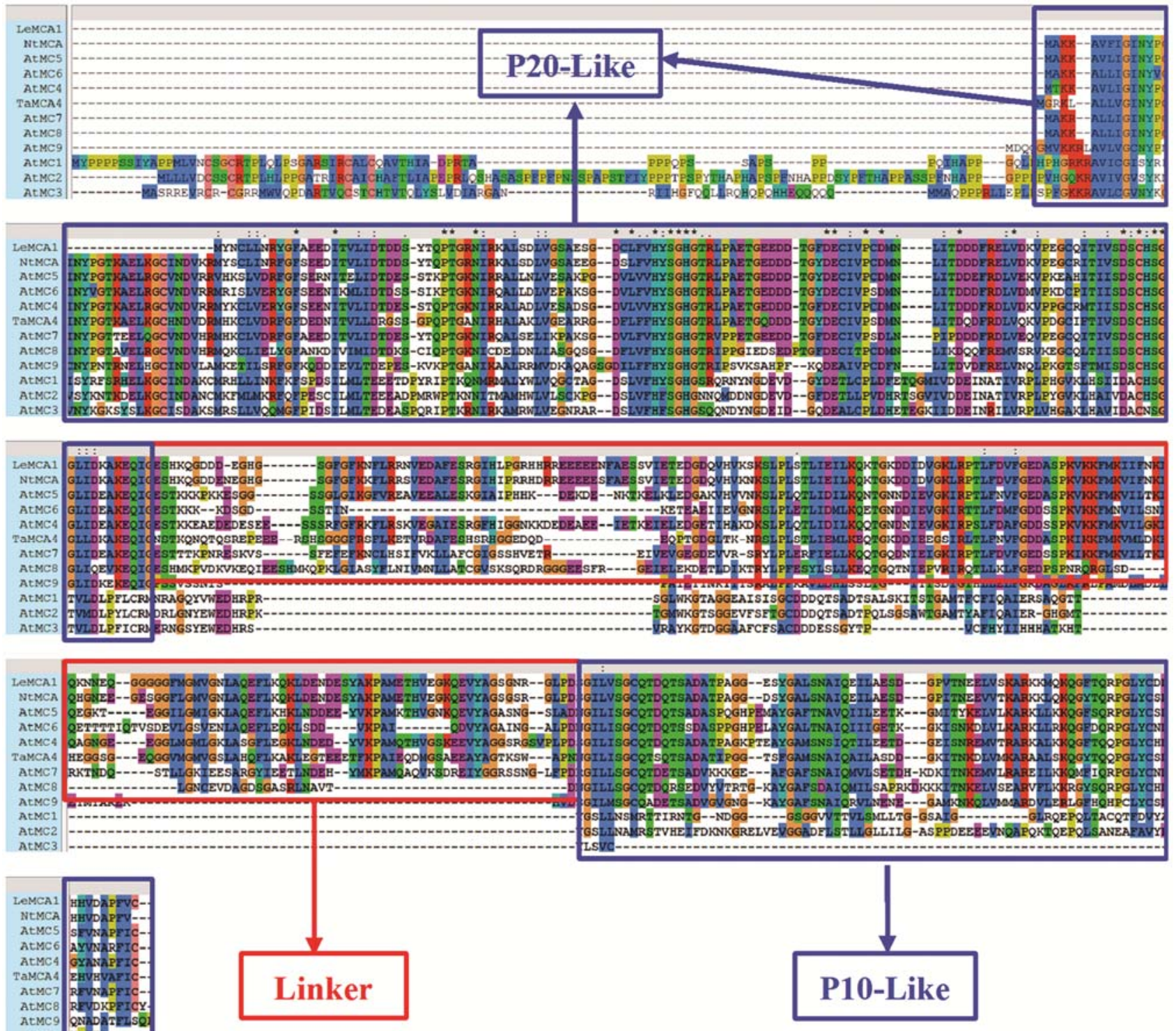

Fig. 2. Multisequence alignment of Triticum aestivum metacaspase 4 (TaMCA4) with other metacaspase proteins. Amino acid sequences from 12 metacaspase genes share similar residues, such as P20-like, Linker, and P10-like domains. 
In this study, we isolated and characterized a wheat metacaspase gene, designated Triticum aestivum metacaspase 4 (TaMCA4), which shares high similarity with type II metacaspase in Arabidopsis thaliana and Nicotiana benthamiana. Transient expression of TaMCA4 in tobacco and wheat leaves did not trigger PCD directly but enhanced the cell death induced by the mouse Bax or the candidate P. striiformis f. sp. tritici effector. Quantitative reverse-transcription polymerase chain reaction (qRT-PCR) analysis revealed that the expression of TaMCA4 was induced in wheat leaves challenged by an avirulent $P$. striiformis $\mathrm{f}$. sp. tritici race CYR23. Knocking down TaMCA4 expression via virus-induced gene silencing (VIGS) enhanced the susceptibility of wheat 'Suwon11' to CYR23 and reduced the necrotic area per infection site. These
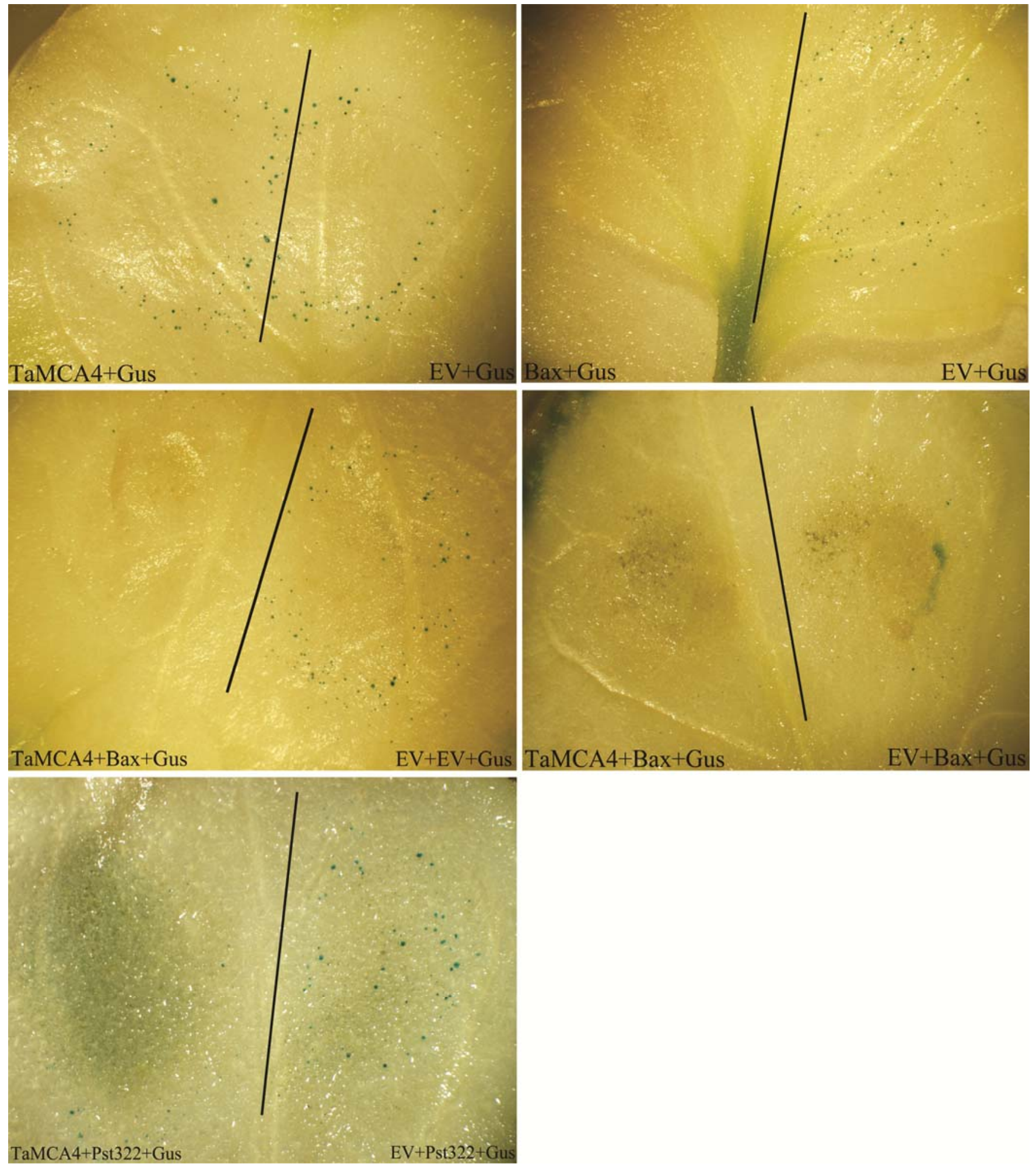

Fig. 3. Transient expression of Triticum aestivum metacaspase 4 (TaMCA4) in Nicotiana benthamiana. TaMCA4 enhanced both Bax-mediated and candidate Puccinia striiformis f. sp. tritici effector-mediated programmed cell death in tobacco leaves bombarded with transient expression vectors as indicated. Black line marks the position of a divider used to prevent the overlap of two bombardment areas. EV, empty vector; $\beta$-glucuronidase (GUS), pUC-GUS; Bax, pUCBax; TaMCA4, pUC-TaMCA4; Pst322, pUC-Pst322. 
results indicate that TaMCA4 functions in the HR triggered in host plants infected by $P$. striiformis f. sp. tritici.

\section{RESULTS}

\section{Cloning and structural features of TaMCA4.}

One cDNA clone from a wheat transcriptome database established previously (unpublished) shared high homology with type II metacaspase genes in A. thaliana (AtMC4, GenBank accession number AY322529) and N. tabacum (NtMC, GenBank accession number EU869285). The sequence information of this clone was used to design primers for amplifying the cDNA fragments of the corresponding gene, which was
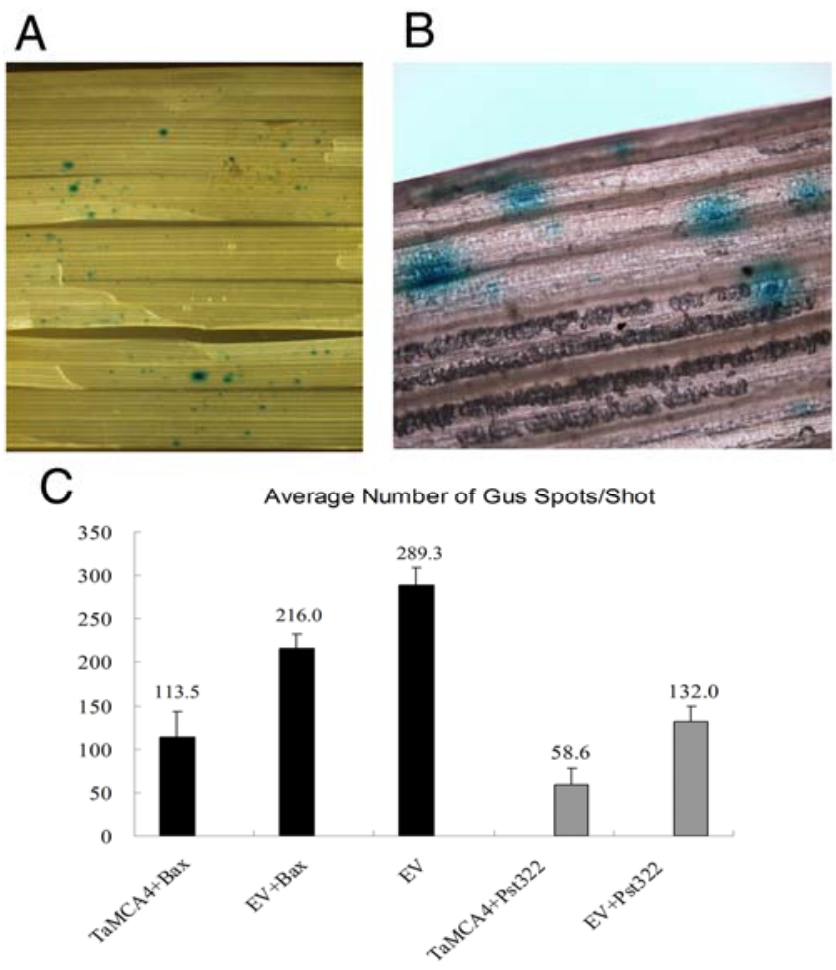

Fig. 4. Transient expression of Triticum aestivum metacaspase 4 (TaMCA4) in T. aestivum. TaMCA4 enhances both Bax-mediated and candidate Puccinia striiformis f. sp. tritici effector-mediated programmed cell death in wheat leaves bombarded with transient expression vectors. EV, pUC empty vector; $\beta$-glucuronidase (GUS), pUC-GUS; Bax, pUC-Bax; TaMCA4, pUC-TaMCA4; Pst322, pUC-Pst322. A, Seven-day-old leaves were prepared to cover the entire bombardment area. Result of Gus staining from one shot with EV and pUC-Gus was shown. B, A large number of Gus spots could be observed by light microscopy and the number for each shot was counted. C, Average number of Gus spots per shot was calculated and a paired sample $t$ test was used to determine the significance of each bombardment. designated TaMCA4. Subsequent analysis by $5^{\prime}$ and $3^{\prime}$ rapid amplification of cDNA ends (RACE) reactions resulted in the cloning of a 1,549-bp-long metacaspase cDNA fragment (GenBank accession number JN807891).

The predicted open reading frame (ORF) of TaMCA4 encodes a protein with 405 amino-acid residues with a molecular weight of approximately $43.9 \mathrm{kDa}$. Multisequence alignment with various full-length metacaspase protein sequences in National Center of Biotechnology Information databases revealed that TaMCA4 is $64.4 \%$ identical to a metacaspase from $N$. tabacum and $61.8 \%$ identical to AtMC4 from A. thaliana (Fig. 1). Compared with type I metacaspase, TaMCA4 contains a much longer linker between the two subunits. Thus, the predicted TaMCA4 is a type II metacaspase (Fig. 2) (Rahman 2010).

\section{TaMCA4 enhances PCD induced by the mouse Bax gene in $N$. benthamiana and $T$. aestivum.}

To determine whether TaMCA4 is involved in plant PCD, we used the double-barreled attachment of the Bio-Rad Gene Gun for co-bombardment assays in $N$. benthamiana (Dou et al. 2008). On tobacco leaves co-bombarded with plasmid pUCGus ( $\beta$-glucuronidase [Gus] reporter gene driven by the Cauliflower mosaic virus [CaMV] 35S promoter), numerous blue spots were observed, which represented the quantity of living cells. Compared with the transient expression of one PCD inducer (mouse Bax gene), tobacco leaves co-bombarded with pUC-TaMCA4 and pUC-Gus vectors had no obvious effects on the formation of blue spots (Fig. 3; Table 1), indicating that TaMCA4 does not induce PCD directly.

Then, TaMCA4 was co-bombarded with Bax to determine whether it enhanced or suppressed PCD triggered by Bax in tobacco leaves. In the first barrel, we combined pUC-TaMCA4,

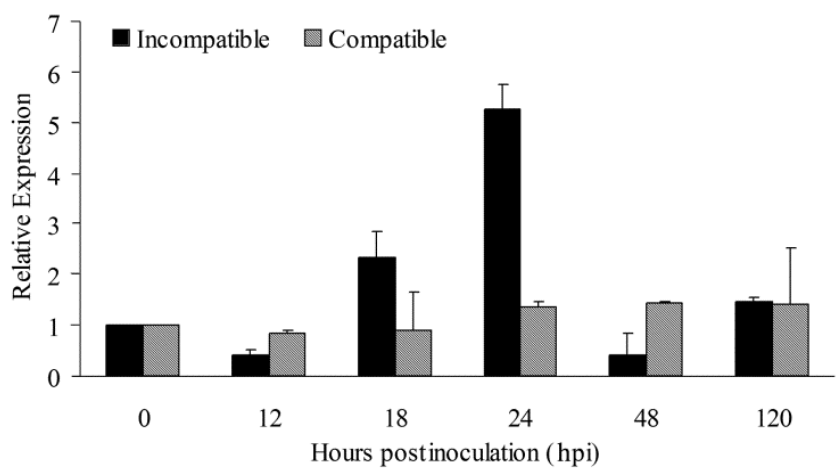

Fig. 5. Transcriptional changes of Triticum aestivum metacaspase 4 (TaMCA4) induced by Puccinia striiformis f. sp. tritici infection. Wheat leaves inoculated with Puccinia striiformis f. sp. tritici races CYR23 (incompatible) and CYR31 (compatible) sampled at $0,12,18,24,48$, and $120 \mathrm{~h}$ postinoculation. Relative expression of TaMCA4 was calculated by the comparative threshold $\left(2^{-\Delta \Delta C T}\right)$ method. Mean and standard deviation were calculated with data from three independent biological replicates.

Table 1. Effect of Triticum aestivum metacaspase 4 (TaMCA4) on Bax-induced and Pst322-induced programmed cell death (PCD)

\begin{tabular}{lllll}
\hline Treatment & \multicolumn{1}{c}{ Barrel 1 $^{\mathbf{x}}$} & \multicolumn{1}{c}{ Barrel 2 $^{\mathbf{x}}$} & ${\text { Mean } \pm \text { SE }^{\mathbf{y}}}$ & Significance $^{\mathbf{z}}$ \\
\hline A & TaMCA4+Gus & EV+Gus & $0.08 \pm 0.04$ & $>0.10$ \\
B & Bax+Gus & EV+Gus & $0.71 \pm 0.09$ & $<0.01$ \\
C & TaMCA4+Bax+Gus & Ev+EV+Gus & $0.84 \pm 0.06$ & $<0.05$ \\
D & TaMCA4+Bax+Gus & Ev+Bax+Gus & $0.37 \pm 0.08$ & $<0.01$ \\
E & TaMCA4+Pst322+Gus & Ev+Pst322+Gus & $0.66 \pm 0.11$ & $<0.01$ \\
\hline
\end{tabular}

${ }^{\mathrm{x}}$ Identical barrels, 1 and 2. EV, empty vector; $\beta$-glucuronidase (GUS), pUC-GUS; Bax, pUC-Bax; TaMCA4, pUC-TaMCA4; and Pst322, pUC-Pst322.

${ }^{y}$ Means and standard error (SE) were calculated from log ratio of barrel 2 versus barrel 1. For each treatment, at least 16 pairs of bombardments were carried out.

${ }^{\mathrm{z}}$ A Wilcoxon signed ranks test was used to analyze the significant differences between different pairs of samples. A significant $P$ value $(P<0.05)$ indicates significant increase in PCD. 
pUC-Bax, and pUC-Gus whereas, in the second barrel, we combined the pUC19 empty vector, pUC-Bax, and pUC-Gus as control. The numbers of blue spots for each bombardment were counted, and a Wilcoxon signed-ranks test was used to analyze the significant differences between different pairs of samples. Tobacco leaves co-bombarded with pUC-TaMCA4, pUC-Bax, and pUC-Gus possessed significantly $(P<0.05)$ fewer blue spots than the control, from which we conclude that TaMCA4 enhances the PCD triggered by the mouse Bax gene in Nicotiana spp. (Fig. 3; Table 1).

Although using the co-bombardment system to determine the function of PCD-related genes is generally accepted (Q. Wang et al. 2011; X. Wang et al. 2011), problems of transient expression of an exogenous gene remains, such as whether different plant species share a similar regulation system of PCD or whether the homologous gene in tobacco influences the results. To solve this problem, we applied a wheat leaf co-bombardment system using one barrel gun shot. For one shot, we mixed pUC-TaMCA4, pUC-Bax, and pUC-Gus; for another, we mixed the pUC19 empty vector, pUC-Bax, and pUC-Gus as control. The number of Gus-expressing spots observed by microscopy in wheat leaves co-bombarded with TaMCA4 and Bax was significantly $(P<0.05)$ less than the control (Fig. 4). Thus, our results are consistent with the conclusion that TaMCA4 enhances PCD triggered by the mouse Bax gene in both $N$. benthamiana and T. aestivum.

\section{TaMCA4 enhances PCD induced}

by the $P$. striiformis $\mathbf{f}$. sp. tritici candidate effector gene, Pst322, in N. benthamiana and T. aestivum.

For better imitation of PCD triggered by infection of the stripe rust pathogen, $P$ st322, a candidate effector gene from $P$. striiformis $\mathrm{f}$. sp. tritici able to trigger PCD in $N$. benthamiana and T. aestivum (C. Tang and Z. Kang, unpublished data), was used to substitute Bax as the inducer of PCD. Tobacco leaves co-bombarded with pUC-TaMCA4, pUC-Pst322, and pUCGus possessed significantly $(P<0.05)$ fewer blue spots than the control (Fig. 3; Table 1); wheat leaves co-bombarded with pUC-TaMCA4, pUC-Pst322, and pUC-Gus possessed significantly $(P<0.05)$ fewer blue spots than the control (Fig. 4$)$. These results indicate that TaMCA4 also enhances the PCD triggered by the candidate effector gene Pst322 in both N. benthamiana and T. aestivum.

\section{Transcriptional changes of TaMCA4 induced by $P$. striiformis f. sp. tritici infection.}

In the seedling stage, Suwon11 wheat shows typical resistant and susceptible phenotypes when inoculated with CYR23 (avirulent) and CYR31 (virulent) races of the stripe rust fungus.

In leaves inoculated with CYR23, the expression level of TaMCA4 was slightly downregulated at $12 \mathrm{~h}$ postinoculation (hpi) compared with that of the 0-hpi control. Expression of TaMCA4 increased at $18 \mathrm{hpi}$ and peaked at $24 \mathrm{hpi}$, then de-

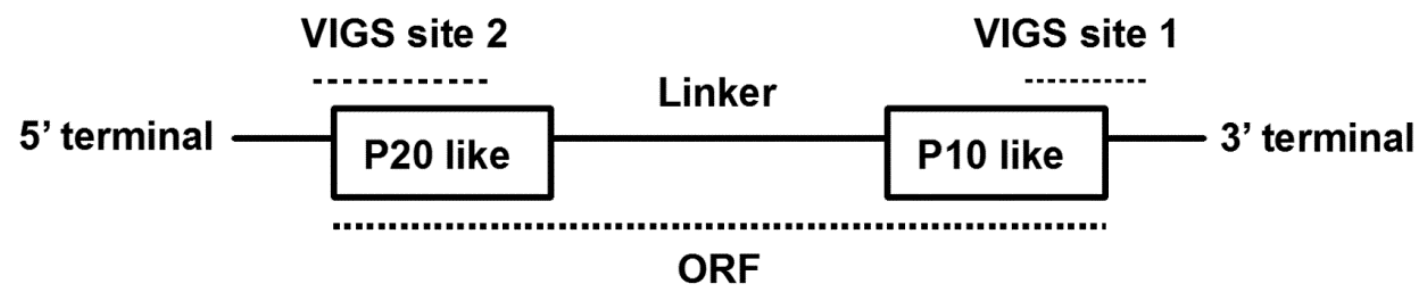

Fig. 6. Two virus-induced gene silencing (VIGS) sites were designed on both sides of Triticum aestivum metacaspase 4 (TaMCA4) to prepare the specific knock-down fragment. ORF $=$ open reading frame.

\section{A Noninoculated}

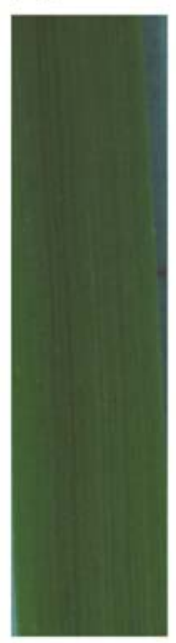

Mock

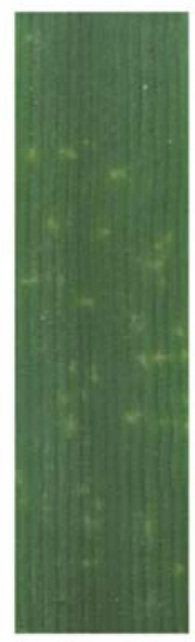

BSMV- 8

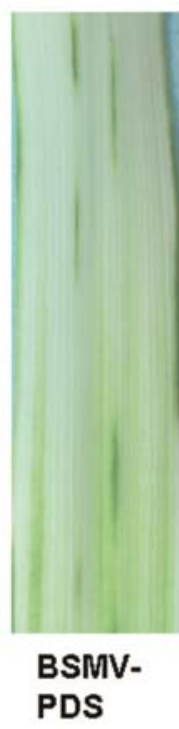

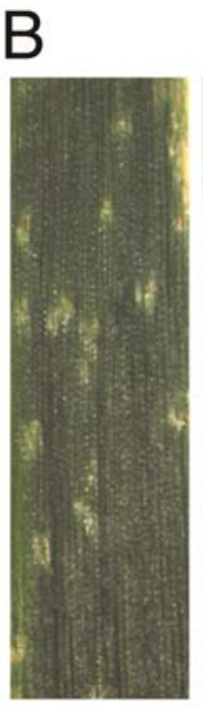

Mock

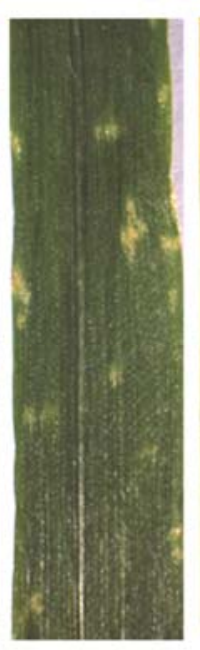

BSMV- $y$
CYR23

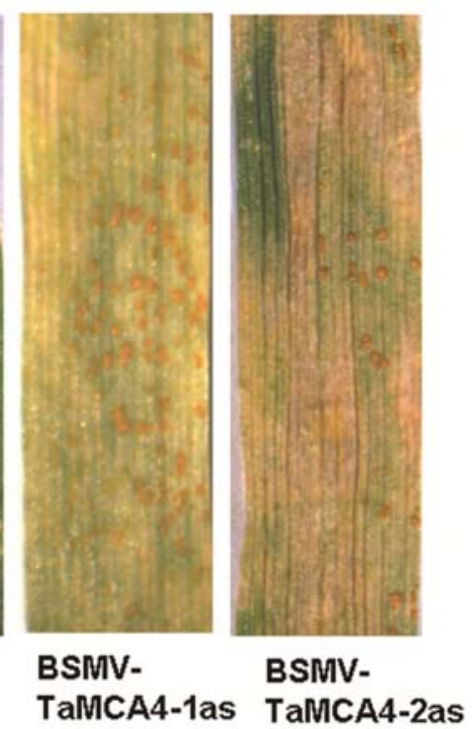

Fig. 7. Functional characterization of Triticum aestivum metacaspase 4 (TaMCA4) by virus-induced gene silencing. A, Mild chlorotic mosaic symptoms on leaves inoculated with Barley stripe mosaic virus (BSMV)- $\gamma$ at 9 days postinoculation (dpi). Photo-bleaching was evident on leaves infected with BSMVTaPDSas at $15 \mathrm{dpi}$ but not on mock-inoculated leaves. Mock: wheat leaves treated with Fes buffer $\left(0.1 \mathrm{M}\right.$ glycine, $0.06 \mathrm{M} \mathrm{K}_{2} \mathrm{HPO}, 1 \%$ wt/vol tetrasodium pyrophosphate, $1 \% \mathrm{wt} / \mathrm{vol}$ bentonite, and 1\% wt/vol celite, $\mathrm{pH}$ 8.5). B, Wheat leaves inoculated with BSMV- $\gamma$, BSMV-TaMCA4-1as, BSMV-TaMCA4-2as, and stripe rust pathogen race CYR23 (avirulent). Typical leaves were photographed at $15 \mathrm{dpi}$. 
creased and remained at the control level from 48 to $120 \mathrm{hpi}$. However, in leaves inoculated with the virulent race CYR31, expression of TaMCA4 was not significantly induced (Fig. 5).

\section{Knocking down expression of TaMCA4 enhances the susceptibility of wheat to $P$. striiformis f. sp. tritici.}

To further characterize the function of TaMCA4 during the interaction between wheat and $P$. striiformis f. sp. tritici, VIGS, an effective reverse genetics tool in barley and wheat, was used (Burch-Smith et al. 2004; Holzberg et al. 2002; Scofield et al. 2005; X. Wang et al. 2011; Zhou et al. 2007). Two pairs of primers were designed to knock down different sites of TaMCA4: TaMCA4-vigs-F1 and TaMCA4-vigs-R1, which amplified a 212-bp fragment located at the terminal of the ORF and 3' untranslated region (UTR); and TaMCA4-vigsF2 and TaMCA4-vigs-R2, which amplified a 397-bp fragment located at the origin of the ORF and $5^{\prime}$ UTR (Fig. 6). These two sites were not conserved between different metacaspase genes, and different DNA fragments were constructed in the original Barley stripe mosaic virus (BSMV)- $\gamma$ vector, designated BSMV-TaMCA4-1 as and BSMV-TaMCA4-2as.

All the BSMV-inoculated plants displayed mild chlorotic mosaic symptoms by 9 days postinoculation (dpi) but had no obvious defects in further leaf growth. To confirm that our VIGS system was functioning correctly, BSMV-TaPDSas (BSMV vector carrying a segment from wheat phytoene desaturase gene) was used as the positive control that generated photobleaching on inoculated plants. Conspicuous HR was elicited by $P$. striiformis f. sp. tritici race CYR23 on leaves preinfected with BSMV- $\gamma$, BSMV-TaMCA4-1as, or BSMV-TaMCA4-2as or mock-inoculated plants. However fungal sporulation around the necrotic spots was limited and observed only on leaves preinfected with BSMV-TaMCA4-1as and BSMV-TaMCA42as by 15 dpi (Fig. 7). Thus, race-specific resistance to the stripe rust fungus was not blocked or eliminated by silencing of TaMCA4. Nevertheless, knocking down TaMCA4 expression resulted in limited fungal growth and uredium development, equivalent to a reduced infection type of the wheat stripe rust fungus.

To determine the efficiency of VIGS, qRT-PCR was used on RNA samples extracted from the fourth leaves of wheat seedlings preinfected by BSMV- $\gamma$, BSMV-TaMCA4-1as, and BSMV-TaMCA4-2as at 24, 48, and 120 hpi with CYR23. Compared with the transcription level of TaMCA4 in leaves

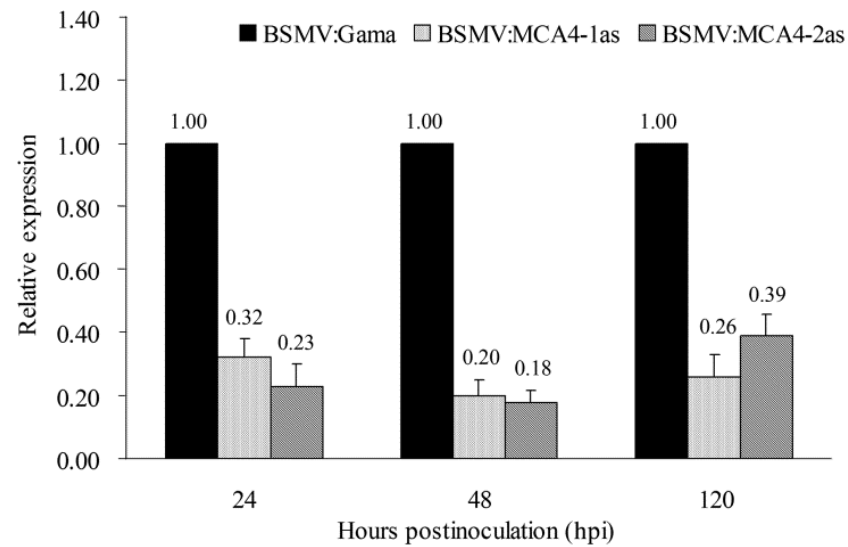

Fig. 8. Relative transcript levels of Triticum aestivum metacaspase 4 (TaMCA4) in knockdown plants assayed by quantitative reverse-transcription polymerase chain reaction. BMSV $=$ Barley stripe mosaic virus. Relative expression of TaMCA4 was calculated by the comparative threshold $\left(2^{-\Delta \Delta \mathrm{CT}}\right)$ method. Mean and standard deviation were calculated with data from three independent replicates. inoculated with BSMV- $\gamma$, the expression of TaMCA4 was reduced 68,80 , and $74 \%$ in leaves inoculated with BSMVTaMCA4-1as at 24, 48, and 120 hpi, respectively; whereas, in leaves inoculated with BSMV-TaMCA4-2as, expression of TaMCA4 was reduced 77, 82, and 61\%, respectively (Fig. 8).

To observe the detailed histological changes associated with enhanced susceptibility of TaMCA4 knocked-down plants to $P$. striiformis f. sp. tritici, leaf segments from at least three plants inoculated with CYR23 were harvested for each sample. Necrotic areas at the infection site were observed at 48 and 120 hpi by microscopy and the proportion of necrotic area was calculated by DP-BSW software (Fig. 9; Table 2). At 48 hpi, necrotic area per infection site in both BSMV-TaMCA4-1as- and BSMV-TaMCA4-2as-infected wheat leaves was significantly $(P<0.01)$ lower than that observed on BSMV- $\gamma$-infected leaves. In addition, the proportion of necrotic areas in BSMVTaMCA4-1as-infected leaves remained at a significantly $(P<$ $0.05)$ lower level at 120 hpi compared with BSMV- $\gamma$-inoculated leaves (Table 2). These results indicate that knocking down TaMCA4 decreases the necrotic areas generated at the infection sites.

Hyphal lengths of stripe rust fungi in BSMV-TaMCA4-1asinfected wheat leaves were significantly $(P<0.05)$ longer than those observed on BSMV- $\gamma$-infected leaves at 120 hpi. Hyphal lengths in BSMV-TaMCA4-2as-infected wheat leaves were significantly $(P<0.01)$ longer than those observed on BSMV$\gamma$-infected leaves at 24 hpi (Table 2). The number of hyphal branches in BSMV-TaMCA4-2as-infected leaves was significantly $(P<0.01)$ more than that in BSMV- $\gamma$-infected leaves at both 24 and 48 hpi (Table 2). These results indicate that knocking down expression of TaMCA4 diminishes plant defense reactions and enhances hyphal growth and branching of the rust fungus.

\section{DISCUSSION}

Our molecular and bioinformatics studies provided strong evidence that TaMCA4 is a typical member of the type II metacaspases. Within plant genomes, nine members of this gene family were found in Arabidopsis and eight in Oryza sativa subsp. japonica (Tsiatsiani et al. 2011). More metacaspase genes may be found in wheat, which possesses a much larger genome than other monocot species.

Transient expression of TaMCA4 in N. benthamiana did not trigger PCD directly but enhanced the frequency of PCD induced by a mammalian Bax gene or candidate $P$. striiformis $\mathrm{f}$. sp. tritici effector gene, indicating that TaMCA4 could neither accomplish the entire process of PCD nor trigger other reactions which may be more essential. Its homologue, AtMCP-2d in Arabidopsis, is shown to be involved in PCD triggered by the mycotoxin FB1, an incompatible bacterial pathogen, or in the presence of photo-oxidative stress inducers (Watanabe and Lam 2011a). Thus, metacaspases become more active only after generation of sufficient signals for PCD reactions, such as the expression of the mammalian Bax gene or pathogen effector gene, $\mathrm{H}_{2} \mathrm{O}_{2}, \mathrm{UV}$, mycotoxin $\mathrm{FB} 1$, and so on. Questions such as whether MCA4 is essential in PCD triggered by various stresses or what specific roles do different metacaspases play remain to be answered.

This study successfully applied the co-bombardment technique on wheat leaves to explore the function of genes involved in PCD. In our preliminary experiments, we attempted to define the suitable variables in both the single-barrel and double-barrel gene gun systems. Perhaps because of the high pressure generated by the double-barrel system and the differences in preparations between the single-barrel and doublebarrel systems, we used different rupture disks and sample 
placement but none generated sufficient Gus-expressing spots in the double-barrel bombardment system (Supplementary Table 2). If the double-barrel system, which is more accurate and precise, can be effectively applied to monocot leaves, investigations of genes involved in PCD and analyses of candidate effectors from pathogens will be facilitated.

According to our previous microscopic studies on the interaction between different races of the stripe rust fungus and Suwon11 wheat, the HR in the incompatible interaction is normally triggered by the initial growth of the hyphae at the infection site between 18 and $48 \mathrm{hpi}$. In the compatible interaction, the fungal hyphae elongate much earlier and faster without triggering the HR (Wang et al. 2007). Hence, qRT-PCR analysis of the changes in transcript provides us reliable evidence that TaMCA4 engages in the HR upon the initial contact of the infection hyphae with the host cell, which is consistent with the positive regulation role of its homologue in Arabidopsis, AtMC4 (Watanabe and Lam 2011a).

Although detailed investigations on the function of AtMC1, AtMC2, and AtMC4 in Arabidopsis have been conducted, regulation of this gene family is still unclear. AtMC4 was reported to exhibit a strict $\mathrm{Ca}^{2+}$ dependence for its catalytic activation, which was apparently mediated by an intramolecular self-cleavage mechanism (Watanabe and Lam 2011b). OsmiR319a.2, an $\mathrm{H}_{2} \mathrm{O}_{2}$-responsive miRNA in rice seedlings, was predicted to target a putative metacaspase $(O s M C A 1)$, although subsequent RACE amplification failed to confirm the prediction (Li et al. 2011). Prediction of the target of the wheat miRNA homologue, TamiR319, did not reveal sequences related to metacaspase genes. Still, it is possible that metacaspase genes are regulated directly by miRNA, which seems to be an efficient and rapid response in plants challenged by different stresses.

Our application on VIGS to further analyze the function of TaMCA4 required a series of modifications to assure that our results were reliable. For example, we used two non-overlapping constructs from different sites of the target gene; microscopic observations of detailed infection process and statistical analyses were combined with phenotype to detect subtle changes generated by knockdown of the target gene; and qRTPCR was applied to measure the efficiency of the VIGS knockdown system.

In both of the two TaMCA4-knockdown plants, necrotic areas observed at $48 \mathrm{hpi}$ were significantly lower than that in the control. Moreover, in the TaMCA4-1as-knockdown plants, necrotic areas remained at a much lower level at $120 \mathrm{hpi}$. The necrotic area triggered by infection of avirulent $P$. striiformis $\mathrm{f}$. sp. tritici race CYR23 was considered to represent the level of the HR. The length of hyphae and the number of branches are important factors that represent the ability of the pathogen to colonize under the stress generated by HR at the infection sites. Suppression of the initial HR may result in longer hyphal and more hyphal branches, as in both of the two TaMCA4knockdown plants, whereas long hyphae and multiple hyphal branches were more effective in triggering HR during the development of the rust fungus, suggesting that TaMCA4-1as is a more successful knockdown genotype. Consistently, a few urediospores could be seen on wheat leaves infected with stripe rust race CYR23 in both of the two TaMCA4-knockdown plants, suggesting that the plant resistance to CYR23 was decreased after knocking down TaMCA4. Thus, at the beginning of the HR, TaMCA4 had been activated and engaged in the ensuing plant defense reaction, which restricted the elongation of the initial hyphae and the formation of haustorial mother cells.

The function of TaMCA4 in resistance toward stripe rust is probably related to its special substrates or self-cleavage activity. Vast efforts and energies have been put into the identification
A
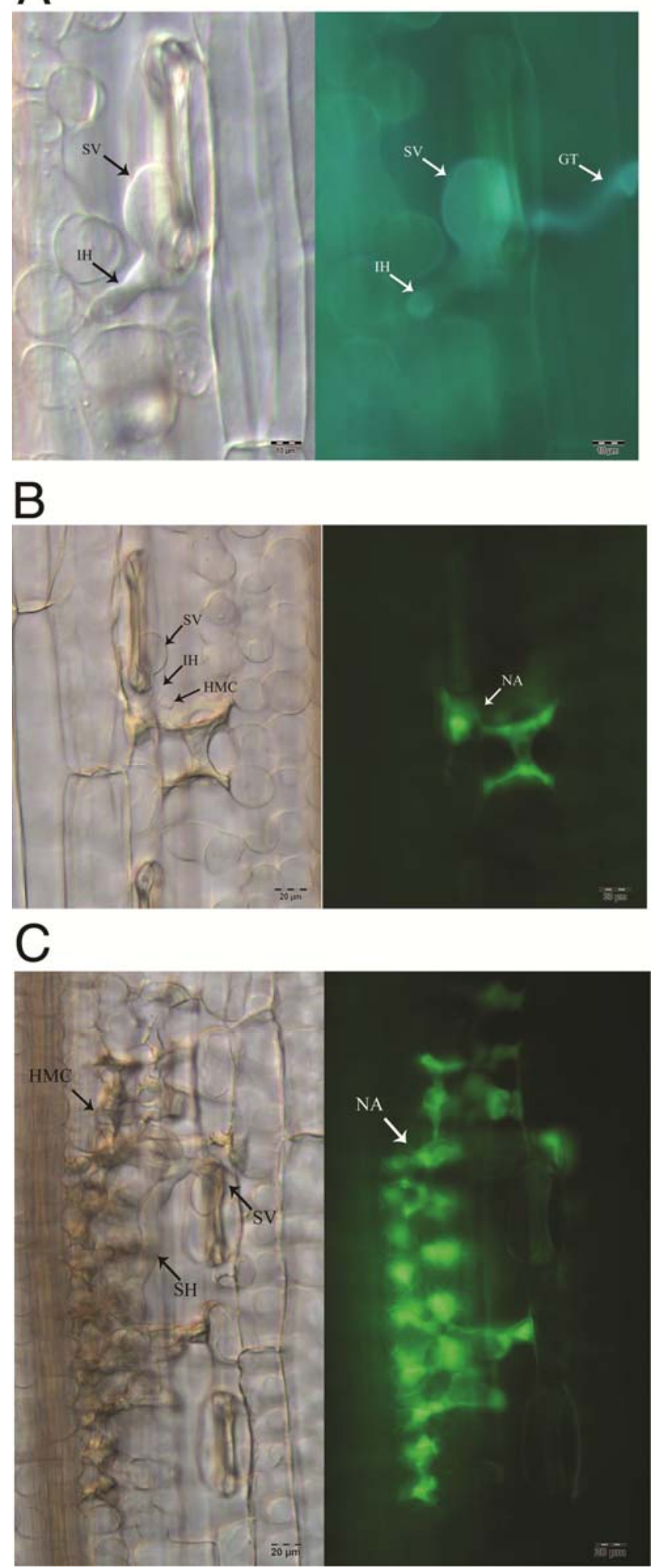

Fig. 9. Histological observation of wheat leaves treated with recombinant Barley stripe mosaic virus (BSMV) viruses and infected with Puccinia striiformis $\mathrm{f}$. sp. tritici avirulent race CYR23. The same infection site was observed by epifluorescence or light microscopy. A, Infection site observed in leaf segment sampled at $24 \mathrm{~h}$ postinoculation (hpi). Only the infection site where substomatal vesicles had formed in the stomata was considered to be successfully penetrated. GT, germ tube; SV, substomatal vesicle; IH, initial hyphae. B, Infection site observed in leaf segment sampled at 48 hpi. The hypersensitive response was triggered by the initial growth of the hyphae at the infection site. NA, necrotic area; HMC, haustorial mother cell. C, Infection site observed in leaf segment sampled at 120 hpi. SH, secondary hyphae. 
of the substrates or self-processing mechanisms of different metacaspases during the last decade. One study demonstrates that VEIDase TSN (AtSerpin1) is one of the substrates of a type II metacaspase in Arabidopsis (Vercammen et al. 2006). Another study shows that active AtMC4 can cleave its inactive form, and in vitro autolysis of AtMC4 could also occur under controlled $\mathrm{Ca}^{2+}$ conditions (Watanabe and Lam 2011b). In conclusion, along with those results of transient expression assay, we demonstrate a very positive role of TaMCA4 during the interaction between wheat and stripe rust.

\section{MATERIALS AND METHODS}

\section{Plant materials, inoculation, and treatments.}

Seedlings of Suwon11 wheat were maintained and inoculated with $P$. striiformis $\mathrm{f}$. sp. tritici race CYR23 (avirulent) or CYR31 (virulent) following the procedures and conditions described previously (Kang and Li 1984). Suwon11, carrying the $\mathrm{YrSu}$ resistance gene, exhibited a typical HR to CYR23 but was highly susceptible to CYR31. Wheat plants inoculated with sterile distilled water were used as mock-inoculation controls. Leaves were harvested at 0, 12, 18, 24, 48, and $120 \mathrm{hpi}$ for RNA isolation. These time points were selected based on previous microscopic studies of the interactions between Suwon11 and CYR23 or CYR31 (Wang et al. 2007). Disease symptoms were scored at $15 \mathrm{dpi}$. All samples were rapidly frozen in liquid nitrogen and stored at $-80^{\circ} \mathrm{C}$. Three independent biological replications were included for each time point.

\section{RNA extraction and qRT-PCR.}

RNA was isolated with the Trizol Reagent (Invitrogen, Carlsbad, CA, U.S.A.) following the instructions provided by the supplier. First-strand cDNA was synthesized with the GoScript Reverse Transcription System (Promega Corp., Madison, WI, U.S.A.). Primers for qRT-PCR were designed and qRT-PCR reactions were conducted as described (Wang et al. 2009). Gene expression was quantified with a 7500 Real-Time PCR System (Applied Biosystems, Foster City, CA, U.S.A.). To avoid variations caused by experimental conditions, the expression level of TaMCA4 in the mockinoculated control was subtracted from that in wheat leaves inoculated with $P$. striiformis f. sp. tritici for analyzing changes in TaMCA4 transcription in the same time-course study. The wheat elongation factor TaEF-1a gene (GenBank accession number Q03033) was used as the internal reference for qRT-PCR analysis. Dissociation curves were generated for each reaction to ensure specific amplification. Threshold values $(\mathrm{Ct})$ generated from the ABI PRISM 7500 Software Tool (Applied Biosystems) were used to quantify relative gene expression by the comparative $2^{-\Delta \Delta \mathrm{CT}}$ method (Livak and Schmittgen 2001).

\section{Isolation of cDNA sequences.}

Primers were designed according to the sequence Unigene15587_All from a wheat transcriptome database (unpublished). Fragments of TaMCA4 were amplified from the first cDNA synthesized with RNA isolated from Suwon11 leaves harvested at 24 hpi with CYR23. The full-length cDNA sequences of TaMCA4 were obtained by sequencing $5^{\prime}$ and $3^{\prime}$ RACE products amplified with the SMART RACE cDNA amplification kit (Clontech Laboratories, Inc., Palo Alto, CA, U.S.A.).

\section{Sequence analysis, alignment, and domain prediction.}

The amino acid sequence of TaMCA4 was analyzed with InterProScan and PROSITE Scan for conserved domains or motifs. TargetIP and TMPRED were used to predict signal peptide and trans-membrane domains. Multiple sequence alignments were created with ClustalW (Thompson et al. 1994). Polygenetic analysis of TaMCA4 and MCA members was carried out by DNAMAN software.

\section{Plasmid construction.}

pUC-TaMCA4 (TaMCA4 driven by the CaMV 35S promoter), pUC-Bax, pUC-Pst322, and pUC-GUS were constructed as described (Dou et al. 2008). Plasmids pUC-TaMCA4 and pUC-Pst322 were obtained by replacing the Bax gene on pUC-Bax with the TaMCA4-ORF and Pst322-ORF fragment, respectively. Sequence information of Pst322 was obtained from the genomic sequencing project conducted previously $(\mathrm{Z}$. Kang and C. Tang, unpublished).

Plasmids used for gene silencing were based on the constructs described (Holzberg et al. 2002). A cDNA fragment (120 bp) of the wheat phytoene desaturase gene TaPDS was obtained by RT-PCR. This fragment, in an antisense orientation, was used to replace the green fluorescent protein (GFP) coding sequence in BSMV-GFP, resulting in BSMV-TaPDSas. With a similar approach, BSMV-TaMCA4-1as was prepared with a 212-bp TaMCA4 cDNA fragment derived from its coding sequence and 3' UTR; BSMV-TaMCA4-2as was prepared with a 397-bp TaMCA4 cDNA fragment derived from its coding sequence and $5^{\prime}$ UTR. All the primers designed for plasmid construction can be found in Supplementary Table 1.

\section{Particle bombardment assays.}

Leaves from 4- to 6-week-old N. benthamiana plants were bombarded using the Bio-Rad He/1000 particle delivery system with a double-barreled extension attached as described (Dou et al. 2008). Plasmid DNA was prepared and resuspended to 5 to $6 \mu \mathrm{g} / \mu \mathrm{l}$ in sterile deionized water. For each treatment, $50 \mu \mathrm{l}$ of tungsten particles at $90 \mathrm{mg} / \mathrm{ml}$ and $25 \mu \mathrm{g}$ of pUC-Gus plasmid were combined with $4.17 \mu \mathrm{g}$ of pUCBax, $6.25 \mu \mathrm{g}$ of pUC-Pst322, $25 \mu \mathrm{g}$ of pUC-TaMCA4, $25 \mu \mathrm{g}$

Table 2. Histological observations during the incompatible interaction between wheat and the stripe rust fungus when the transcription of Triticum aestivum metacaspase 4 (TaMCA4) is repressed ${ }^{\mathrm{v}}$

\begin{tabular}{|c|c|c|c|c|c|c|c|c|}
\hline \multirow[b]{2}{*}{ Treatment $^{\mathrm{z}}$} & \multicolumn{2}{|c|}{ Necrotic area $^{w}$} & \multicolumn{3}{|c|}{ Hyphal length ${ }^{x}$} & \multicolumn{3}{|c|}{ Branches $^{\mathrm{y}}$} \\
\hline & 48 hpi & 120 hpi & 24 hpi & 48 hpi & 120 hpi & 24 hpi & 48 hpi & 120 hpi \\
\hline BSMV- $\gamma$ & $2.91 \mathrm{a}$ & $4.59 \mathrm{a}$ & $0.42 \mathrm{a}$ & $0.50 \mathrm{a}$ & $1.50 \mathrm{a}$ & $1.02 \mathrm{a}$ & $0.92 \mathrm{a}$ & $2.88 \mathrm{a}$ \\
\hline BSMV-TaMCA4-1as & $1.52 \mathrm{~b}^{*}$ & $3.18 \mathrm{~b}$ & $0.46 \mathrm{a}$ & $0.51 \mathrm{a}$ & $1.80 \mathrm{~b}$ & $0.85 \mathrm{a}$ & $1.16 \mathrm{a}$ & $2.94 \mathrm{a}$ \\
\hline BSMV-TaMCA4-2as & $2.04 \mathrm{~b}^{*}$ & $5.89 \mathrm{a}$ & $0.53 \mathrm{~b}^{*}$ & $0.50 \mathrm{a}$ & $1.49 \mathrm{a}$ & $1.87 \mathrm{~b}^{*}$ & $1.43 \mathrm{~b}^{*}$ & $2.78 \mathrm{a}$ \\
\hline
\end{tabular}

\footnotetext{
${ }^{\mathrm{v}}$ Analysis of significance was calculated according to paired sample $t$ test method ( $\mathrm{b}^{*}$ and $\mathrm{b}$ indicate $P<0.01$ and 0.05 , respectively); hpi $=$ h postinoculation.

${ }^{\mathrm{w}}$ Average area of necrotic mesophyll cells calculated from at least 50 infection sites (units in 1,000 $\mu \mathrm{m}^{2}$, measured by DP-BSW software).

${ }^{\mathrm{x}}$ Average distance from the base of substomatal vesicles to hyphal tips calculated from at least 50 infection sites (units in $100 \mu \mathrm{m}$, measured by DP-BSW software).

y Average number of hyphal branches calculated from at least 50 infection sites.

${ }^{\mathrm{z}}$ Barley stripe mosaic virus (BSMV)- $\gamma$, BSMV-TaMCA4-1as, and BSMV-TaMCA4-2-as: leaves preinfected with recombinant BSMV followed by inoculation with Puccinia striiformis f. sp. tritici race CYR23.
} 
of pUC-TaMCA4, $4.17 \mu \mathrm{g}$ of pUC-Bax plus $25 \mu \mathrm{g}$ of pUCTaMCA4, or $6.25 \mu \mathrm{g}$ of pUC-Pst322 plus $25 \mu \mathrm{g}$ of pUCTaMCA4, whereas equal quantities of empty vector plasmids were used for substitution as control. Then, $25 \mu \mathrm{l}$ of Spermidine at $0.1 \mathrm{~mol} / \mathrm{liter}$ and $65 \mu \mathrm{l}$ of $\mathrm{CaCl}_{2}$ at $2.5 \mathrm{~mol} / \mathrm{liter}$ were added and incubated for 10 to $20 \mathrm{~min}$ at $4^{\circ} \mathrm{C}$. Samples were centrifuged at $14,000 \mathrm{rpm}$ for $30 \mathrm{~s}$ and the supernatant was partially removed, leaving $30 \mu \mathrm{l}$ for bombardment. For shooting, $1 \mu \mathrm{l}$ of particle mixture and $1 \mu \mathrm{l}$ of control mixture were loaded on the microcarrier as described.

After co-bombardment, leaves were incubated at $28^{\circ} \mathrm{C}$ for 2 days in darkness and then stained for $16 \mathrm{~h}$ at $28^{\circ} \mathrm{C}$ using 5bromo-4-chloro-3-indolyl-D-glucuronic acid at $0.8 \mathrm{mg} / \mathrm{ml}, 80$ $\mathrm{mM} \mathrm{Na}$ phosphate $(\mathrm{pH} 7.0), 0.4 \mathrm{mM} \mathrm{K} \mathrm{K}_{3} \mathrm{Fe}(\mathrm{CN})_{6}, 0.4 \mathrm{mM}$ $\mathrm{K}_{4} \mathrm{Fe}(\mathrm{CN})_{6}, 8 \mathrm{mM} \mathrm{Na}{ }_{2}$ EDTA, $20 \%$ methanol, and $0.06 \%$ (vol/vol) TritonX-100. After bleaching in $100 \%$ methanol for $12 \mathrm{~h}$, blue spots were counted by a dissecting microscopy. A large number of Gus spots could be observed by microscopy and the number for each shot was counted. A Wilcoxon signed ranks test was used to analyze the significant differences between different pairs of samples by SPSS software. Each assay consisted of eight pairs of shots and was conducted at least twice.

For wheat leaf co-bombardment, leaves from 7-day-old plants of Suwon11 were placed tightly in dishes and shot with the Bio-Rad He/1000 single-barreled particle delivery system. DNA was prepared according to the shooting protocol described previously (Douchkov et al. 2005; Schweizer et al. 2000). For different treatments, $7 \mu \mathrm{g}$ of pUC-Gus, $7 \mu \mathrm{g}$ of pUC-TaMCA4 or pUC empty vector, and $1.4 \mu \mathrm{g}$ of pUC-Bax or pUC-Pst322, were mixed with $26.7 \mu \mathrm{l}$ of tungsten particles at $90 \mathrm{mg} / \mathrm{ml}$ and an equal volume of $\mathrm{Ca}\left(\mathrm{NO}_{3}\right)_{2}$ in a 1.5-ml Eppendorf tube and incubated for 10 to $30 \mathrm{~min}$ at room temperature by inverting periodically. Samples were centrifuged at $14,000 \mathrm{rpm}$ for $30 \mathrm{~s}$ and the supernatant was removed. Then, $1 \mathrm{ml}$ of $96 \%$ ethanol was used to wash the samples twice and, finally, the pellet was resuspended in $30 \mu \mathrm{l}$ of $96 \%$ ethanol. For shooting, $4 \mu \mathrm{l}$ of the DNA-tungsten mixture was distributed into each macro-carrier. During the bombardment, we used a 650-psi rupture disk and placed the leaf samples on the third column as described (Supplementary Fig. 1). Staining and bleaching methods were similar to those described above. A large number of Gus spots could be observed by microscopy and the number for each shot was counted. A paired-sample $t$ test was used to analyze the significant differences between different treatments by SPSS software. Each assay consisted of seven shots and was conducted at least twice.

\section{BSMV-mediated TaMCA4 gene silencing.}

Capped in vitro transcripts were prepared from linearized plasmids containing the tripartite BSMV genome (Petty et al. 1990) using the mMessage $\mathrm{T} 7$ in vitro transcription kit (Ambion, Austin, TX, U.S.A.) following the manufacturer's instructions. Three independent sets of plants were prepared for each of the four BSMV virus constructs (BSMV- $\gamma$, BSMV-TaPDSas, BSMV-TaMCA4-1as, and BSMV-TaMCA4-2as), with a total of 72 seedlings. Another 24 seedlings mock inoculated with $1 \times$ Fes buffer $\left(0.1 \mathrm{M}\right.$ glycine, $0.06 \mathrm{M} \mathrm{K}_{2} \mathrm{HPO}_{4}, 1 \% \mathrm{wt} / \mathrm{vol}$ tetrasodium pyrophosphate, $1 \% \mathrm{wt} / \mathrm{vol}$ bentonite, and $1 \% \mathrm{wt} / \mathrm{vol}$ celite, $\mathrm{pH}$ 8.5) served as the control. The second leaf of a two-leaf wheat seedling was inoculated with BSMV transcripts by gently rubbing the surface with a gloved finger (Hein et al. 2005; Holzberg et al. 2002; Scofield et al. 2005), maintained in a growth chamber at $23 \pm 2{ }^{\circ} \mathrm{C}$, and examined for symptoms at regular intervals. Once the virus phenotype was observed, the fourth leaf was inoculated with urediospores of pathotype CYR23. Infection types of stripe rust were recorded at $15 \mathrm{dpi}$.
The fourth leaves were also sampled at 0, 24, 48, and $120 \mathrm{hpi}$ for histological observation and RNA isolation.

\section{Histological observations \\ of fungal growth and host response.}

Wheat leaves infected with BSMV were sampled at 24, 48, and 120 hpi with $P$. striiformis f. sp. tritici and stained as described (Wang et al. 2007). Cleared leaf segments were examined with an Olympus BX-51 microscope (Olympus Corp., Tokyo) for infection sites. Auto-fluorescence of mesophyll cells in infected leaves was measured as necrotic area by epifluorescence microscopy (excitation filter, $485 \mathrm{~nm}$; dichromic mirror, $510 \mathrm{~nm}$; and barrier filter, $520 \mathrm{~nm}$ ). At least 50 infection sites were examined for each of five randomly selected leaf segments per treatment. Only an infection site where substomatal vesicles had formed in the stomata was considered to be successfully penetrated. The proportions of necrotic areas, hyphae length, and hyphae branches were observed by microscopy and calculated by DP-BSW software. Standard deviations and a paired sample $t$ test for statistical analysis were performed with the SPSS software.

\section{ACKNOWLEDGMENTS}

This work was supported by National Natural Science Foundation of China [number 30930064], the earmarked fund for China Agriculture Research System (number CARS-3-1-11), and the 111 Project from Ministry of Education of China (number B07049). We thank L. Dunkle from the United States Department of Agriculture-Agricultural Research Service at Purdue University for critically reading the manuscript, P. Schweizer from Leibniz-Institute of Plant Genetics and Crop Plant Research for providing detailed shooting protocol of particle bombardment in monocot leaves, S. R. Scofield for providing BSMV vectors, and D. Dou for providing transient expression vectors.

\section{LITERATURE CITED}

Burch-Smith, T. M., Anderson, J. C., Martin, G. B., and Dinesh-Kumar, S. P. 2004. Applications and advantages of virus-induced gene silencing for gene function studies in plants. Plant J. 39:734-746.

Carmona-Gutierrez, D., Fröhlich, K., Kroemer, G., and Madeo, F. 2010. Metacaspases are caspases. Doubt no more. Cell Death Differ. 17:377378.

Chen, X., Moore, M., Milus, E.A., Long, D. L., Line, R. F., Marshall, D., and Jackson, L. 2002. Wheat stripe rust epidemics and races of Puccinia striiformis f. sp. tritici in the United States in 2000. Plant Dis. 86:39-46.

Coll, N., Epple, P., and Dangl, J. 2011. Programmed cell death in the plant immune system. Cell Death Differ. 18:1247-1256.

Coll, N. S., Vercammen, D., Smidler, A., Clover, C., Van Breusegem, F., Dangl, J. L., and Epple, P. 2010. Arabidopsis type I metacaspases control cell death. Science 330:1393.

Das, A., Kawai-Yamada, M., and Uchimiya, H. 2010. Programmed cell death in plants. Pages 371-383 in: Abiotic Stress Adaptation in Plants. Springer, Dordrecht, The Netherlands.

Dou, D., Kale, S. D., Wang, X., Chen, Y., Wang, Q., Jiang, R. H. Y., Arredondo, F. D., Anderson, R. G., and Thakur, P. B. 2008. Conserved C-terminal motifs required for avirulence and suppression of cell death by Phytophthora sojae effector Avrlb. Plant Cell Online 20:1118.

Douchkov, D., Nowara, D., Zierold, U., and Schweizer, P. 2005. A highthroughput gene-silencing system for the functional assessment of defense-related genes in barley epidermal cells. Mol. Plant-Microbe Interact. 18:755-761.

Enoksson, M., and Salvesen, G. 2010. Metacaspases are not caspasesalways doubt. Cell Death Differ. 17:1221.

Geske, F. J., and Gerschenson, L. E. 2001. The biology of apoptosis. Hum. Pathol. 32:1029-1038.

He, R., Drury, G. E., Rotari, V. I., Gordon, A., Willer, M., Farzaneh, T., Woltering, E. J., and Gallois, P. 2008. Metacaspase-8 modulates programmed cell death induced by ultraviolet light and $\mathrm{H}_{2} \mathrm{O}_{2}$ in Arabidopsis. J. Biol. Chem. 283:774-783.

Hein, I., Barciszewska-Pacak, M., Hrubikova, K., Williamson, S., Dinesen, M., Soenderby, I. E., Sundar, S., Jarmolowski, A., Shirasu, K., and Lacomme, C. 2005. Virus-induced gene silencing-based functional 
characterization of genes associated with powdery mildew resistance in barley. Plant Physiol. 138:2155

Hoeberichts, F. A., Have, A., and Woltering, E. J. 2003. A tomato metacaspase gene is upregulated during programmed cell death in Botrytis cinerea-infected leaves. Planta 217:517-522.

Holzberg, S., Brosio, P., Gross, C., and Pogue, G. P. 2002. Barley stripe mosaic virus-induced gene silencing in a monocot plant. Plant $\mathrm{J}$. 30:315-327.

Kang, Z., and Li, Z. 1984. Discovery of a normal T. type new pathogenic strain to Lovrin10. Acta Cllegii Septentrionali Occidentali Agric. 4:1828.

Katagiri, F., and Tsuda, K. 2010. Understanding the plant immune system. Mol. Plant-Microbe Interact. 23:1531-1536.

Kitanaka, C., and Kuchino, Y. 1999. Caspase-independent programmed cell death with necrotic morphology. Cell Death Differ. 6:508.

Kroemer, G., and Martin, S.J. 2005. Caspase-independent cell death. Nat. Med. 11:725-730

Li, T., Li, H., Zhang, Y. X., and Liu, J. Y. 2011. Identification and analysis of seven $\mathrm{H}_{2} \mathrm{O}_{2}$-responsive miRNAs and 32 new miRNAs in the seedlings of rice (Oryza sativa L. ssp. indica). Nucleic Acids Res. 39:2821.

Livak, K. J., and Schmittgen, T. D. 2001. Analysis of relative gene expression data using real-time quantitative PCR and the 2-[Delta][Delta] CT method. Methods 25:402-408.

Madeo, F., Herker, E., Maldener, C., Wissing, S., Lächelt, S., Herlan, M., Fehr, M., Lauber, K., Sigrist, S.J., and Wesselborg, S. 2002. A caspaserelated protease regulates apoptosis in yeast. Mol. Cell 9:911-917.

Petty, I., French, R., Jones, R., and Jackson, A. 1990. Identification of barley stripe mosaic virus genes involved in viral RNA replication and systemic movement. EMBO (Eur. Mol. Biol. Organ.) J. 9:3453.

Rahman, M. 2010. Biochemical analysis of type II Metacaspase ( $m c I I-P a)$ Masters thesis. Swedish University of Agricultural Sciences, Uppsala, Sweden.

Schweizer, P., Pokorny, J., Schulze-Lefert, P., and Dudler, R. 2000. Double-stranded RNA interferes with gene function at the single-cell level in cereals. Plant J. 24:895-903.

Scofield, S. R., Huang, L., Brandt, A. S., and Gill, B. S. 2005. Development of a virus-induced gene-silencing system for hexaploid wheat and its use in functional analysis of the Lr21-mediated leaf rust resistance pathway. Plant Physiol. 138:2165.

Thompson, J. D., Higgins, D. G., and Gibson, T. J. 1994. CLUSTAL W: improving the sensitivity of progressive multiple sequence alignment through sequence weighting, position-specific gap penalties and weight matrix choice. Nucleic Acids Res. 22:4673.
Tsiatsiani, L., Van Breusegem, F., Gallois, P., Zavialov, A., Lam, E., and Bozhkov, P. 2011. Metacaspases. Cell Death Differ. 18:1279-1288.

Van Baarlen, P., Woltering, E. J., Staats, M., and Van Kan, J. A. L. 2007. Histochemical and genetic analysis of host and non-host interactions of Arabidopsis with three Botrytis species: an important role for cell death control. Mol. Plant Pathol. 8:41-54.

Vercammen, D., Belenghi, B., Van De Cotte, B., Beunens, T., Gavigan, J. A., De Rycke, R., Brackenier, A., Inzé, D., Harris, J. L., and Van Breusegem, F. 2006. Serpin1 of Arabidopsis thaliana is a suicide inhibitor for metacaspase 9. J. Mol. Biol. 364:625-636.

Wang, C. F., Huang, L. L., Buchenauer, H., Han, Q. M., Zhang, H. C., and Kang, Z. S. 2007. Histochemical studies on the accumulation of reactive oxygen species $\left(\mathrm{O}^{2-}\right.$ and $\left.\mathrm{H}_{2} \mathrm{O}_{2}\right)$ in the incompatible and compatible interaction of wheat-Puccinia striiformis f. sp. tritici. Physiol. Mol. Plant Pathol. 71:230-239.

Wang, Q., Han, C., Ferreira, A. O., Yu, X., Ye, W., Tripathy, S., Kale, S. D., Gu, B., Sheng, Y., and Sui, Y. 2011. Transcriptional programming and functional interactions within the Phytophthora sojae RXLR effector repertoire. Plant Cell 23:2064-2086.

Wang, X., Tang, C., Zhang, G., Li, Y., Wang, C., Liu, B., Qu, Z., Zhao, J., Han, Q., and Huang, L. 2009. cDNA-AFLP analysis reveals differential gene expression in compatible interaction of wheat challenged with Puccinia striiformis f. sp. tritici. BMC Genomics 10:289.

Wang, X., Tang, C., Zhang, H., Xu, J. R., Liu, B., LV, J., Han, D., Huang, L., and Kang, Z. 2011. TaDAD2, a negative regulator of programmed cell death, is important for the interaction between wheat and the stripe rust fungus. Mol. Plant-Microbe Interact. 24:79-90.

Watanabe, N., and Lam, E. 2005. Two Arabidopsis metacaspases $A t M C P 1 b$ and AtMCP $2 b$ are arginine/lysine-specific cysteine proteases and activate apoptosis-like cell death in yeast. J. Biol. Chem. 280:1469114699.

Watanabe, N., and Lam, E. 2011a. Arabidopsis metacaspase 2d is a positive mediator of cell death induced during biotic and abiotic stresses. Plant J. 66:969-982.

Watanabe, N., and Lam, E. 2011b. Calcium-dependent activation and autolysis of Arabidopsis metacaspase 2d. J. Biol. Chem. 286:10027.

Woltering, E.J. 2004. Death proteases come alive. Trends Plant Sci. 9:469472.

Zhou, H., Li, S., Deng, Z., Wang, X., Chen, T., Zhang, J., Chen, S., Ling, H., Zhang, A., and Wang, D. 2007. Molecular analysis of three new receptor-like kinase genes from hexaploid wheat and evidence for their participation in the wheat hypersensitive response to stripe rust fungus infection. Plant J. 52:420-434. 